\title{
Review Article \\ Robotic Radical Prostatectomy in Patients with Previous Prostate Surgery and Radiotherapy
}

\author{
Ömer Acar' ${ }^{1}$ and Tarık Esen ${ }^{1,2}$ \\ ${ }^{1}$ Department of Urology, VKF American Hospital, 34365 Istanbul, Turkey \\ ${ }^{2}$ School of Medicine, Koc University, 34450 Istanbul, Turkey \\ Correspondence should be addressed to Ömer Acar; omer_acar_@hotmail.com \\ Received 10 April 2014; Revised 23 June 2014; Accepted 23 June 2014; Published 9 July 2014 \\ Academic Editor: Katsuto Shinohara \\ Copyright (C) 2014 Ö. Acar and T. Esen. This is an open access article distributed under the Creative Commons Attribution License, \\ which permits unrestricted use, distribution, and reproduction in any medium, provided the original work is properly cited.

\begin{abstract}
Herein, we will review the available literature about robot-assisted radical prostatectomy in patients who have undergone prostate surgery or radiotherapy. Current data about this topic consists of small case series with limited follow-up. Despite being technically demanding, robot-assisted radical prostatectomy (RARP) can be considered feasible in either setting. Prostate surgery or prostatic irradiation should not be considered as a contraindication for robot-assisted radical prostatectomy. Nevertheless, patient counseling about the possible complications and the need for reintervention is of extreme importance in this patient population. Early oncologic and functional results of RARP performed in case of radiorecurrent prostate cancer look promising. Regarding postprostate surgery RARP, some series have reported comparable results, while some have demonstrated more inferior outcomes than those of naive cases. In order to assess the exact functional and oncologic outcome of RARP in patients with previous prostate
\end{abstract} \\ surgery and radiotherapy, studies enrolling higher number of patients and providing longer follow-up data are needed.
}

\section{Introduction}

Radical prostatectomy (RP) after previous treatments to the prostate such as transurethral resection of the prostate (TURP), photoselective vaporization (PVP), external-beam radiotherapy (EBRT), and brachytherapy (BT) is widely considered to be a more challenging task than in a prostate that has not been manipulated surgically or affected by radiotherapy. It is considered that previous prostatic resection or irradiation may hinder optimal results for radical prostatectomy in several ways. Most importantly, perioperative difficulties in defining correct surgical planes will increase the likelihood of significant complications and positive surgical margins. Additionally, functional outcomes related to erectile function and continence are at risk, due to the relative inability to identify and preserve neurovascular structures.

With increasing experience and the proven efficacy of robot-assisted radical prostatectomy (RARP), more complex cases such as those with previous TURP or radiotherapy (RT) are also being investigated using this technique. This review will focus on the perioperative, functional, and oncologic outcomes of robot-assisted radical prostatectomy, performed after prostate surgery or radiotherapy.

\section{Robot-Assisted Radical Prostatectomy after Radiation Failure}

2.1. Radiotherapy for Prostate Cancer. In localized prostate cancer (T1c-T2 N0 M0), three-dimensional (3D) conformal radiotherapy, with or without intensity modulated radiotherapy (IMRT), is recommended even for young patients who refuse surgical intervention. Irradiation offers the same longterm survival results as radical prostatectomy; moreover, EBRT provides a quality of life (QoL) at least as good as that provided by surgery [1]. Transperineal low-dose rate BT is another safe and effective technique that might be used to treat low-risk prostate cancer [2]. The eligibility criteria are stage cT1-T2a N0 M0, a Gleason score of 6 or lower assessed on a sufficient number of random biopsies, an initial PSA level of $10 \mathrm{ng} / \mathrm{mL}$ or lower, $50 \%$ or fewer of biopsy cores involved with cancer, a prostate volume of $50 \mathrm{~mL}$ or less, and 
a good IPSS. Recurrence-free survival after 5 and 10 years has been reported to range from $71 \%$ to $93 \%$ and from $65 \%$ to $85 \%$ [2].

According to the American Society for Therapeutic Radiology and Oncology (ASTRO) criteria, biochemical failure is defined as a PSA rise of $2 \mathrm{ng} / \mathrm{mL}$ above the posttreatment nadir, whether or not the patient received hormonal therapy in conjunction with radiation therapy [3].

Routine prostate biopsy should not be ordered for the evaluation of PSA-only recurrences, according to an ASTRO consensus recommendation [3]. On the other hand, prostate biopsy documenting local recurrence represents the main cornerstone in the decision-making process for salvage RP in patients with rising PSA levels following a nadir after radiation therapy. It is a general recommendation to wait about 18 months after radiation therapy or seed implantation [4]. Patients with rising PSA and viable cancer on biopsy 2 years after radiation therapy have true locally recurrent disease and might be candidates for salvage RP.

\subsection{Therapeutic Options after Radiation Failure. In case of} radiorecurrent $\mathrm{PCa}$, treatment options include salvage radical prostatectomy (SRP), cryotherapy, high-intensity focused ultrasound (HIFU), and salvage BT $[4,5]$. According to data from the Cancer of the Prostate Strategic Urological Research Endeavor (CaPSURE) database, 5277 men with PCa underwent RP (4342 men) or RT (935 men). In the latter group, 587 patients $(63 \%)$ developed recurrent disease or received secondary treatment after a mean follow-up of 38 months [6]. Ninety-two percent of the patients in the CaPSURE database, who had radiorecurrent prostate cancer, received systemic ADT while only $2 \%$ of the patients underwent salvage RP [6]. Thus, more than $90 \%$ of the patients were placed on salvage hormonal therapy which is noncurative, indefinite, and associated with its own side effects and quality of life concerns such as hot flashes, sexual dysfunction, reduction in muscle mass, increased fracture risk, insulin resistance, and cardiovascular morbidity. The underutilization of salvage RP may be explained by its technically demanding nature and the fact that RT-induced cystitis, fibrosis, and tissue plane obliteration can increase the probability of complications with rectal injury, urinary incontinence, erectile dysfunction, and anastomotic contracture being reported in a substantial proportion of the cases [7-9]. However, in well-selected patients, the procedure may result in long-term disease-free survival.

2.3. General Considerations about Salvage Radical Prostatectomy. A candidate for salvage RP should fulfill the following requirements: surgically curable disease at initial radiation, no evidence of metastatic disease, a postradiation biopsy confirming PCa, and a life expectancy long enough ( $\geq 10$ years) to benefit from intervention. Presurgical PSA $(<10 \mathrm{ng} / \mathrm{mL})$ and Gleason score of the postradiation biopsy $(\leq 7)$ should also be considered when selecting a patient for salvage therapy $[4,10]$. The first series of salvage RP and cystoprostatectomy following radiation failure was published in 1985 by Mador et al. [11]. The initial series reporting on salvage RP have included patients treated in the pre-PSA era without modern radiotherapeutic techniques, when local recurrences were usually detected at a late stage. Consequently, as high as $65 \%$ of the patients suffered from treatment-related morbidities. Up to $60 \%$ of patients who underwent salvage RP had to undergo anterior or total exenteration for locally extensive disease, associated with a high rate of local recurrences and a mean time of progression of only 1.3 years $[4,12]$. Since then, salvage surgery has been used with increasing relative success.

Reports that have been published in the era of modern radiotherapy have described far more optimistic outcomes after salvage RP. In the recent literature review analyzing the currently available data on salvage RP, Chade et al. [10] reported that positive surgical margins varied from $43 \%$ to $70 \%$ in the earlier series and from $0 \%$ to $36 \%$ in the later studies (publication date before or after 2000). Pathologic organ-confined disease was reported in 22-53\% and $25-81 \%$ of studies, respectively. At 10 years, biochemical recurrence-free probability ranged from $28 \%$ to $53 \%$. Series from single centers reported probabilities of cancer-specific survival (CSS) from $70 \%$ to $79 \%$ at 10 years, while the multiinstitutional study reported an $83 \%$ CSS at 10 years. Overall survival (OS) varied from $54 \%$ to $89 \%$ at 10 years [10].

Before SRP, PSA may be considered as the strongest prognostic factor predicting the oncologic outcome after salvage RP, because it was shown to significantly predict progression-free survival (PFS), CSS, and OS in most of the series [13-16]. Clinical stage before the commencement of RT [17], Gleason score prior to salvage RP, percentage of positive cores at biopsy, PSA doubling time, and low-dose brachytherapy were the other reported variables that have the potential to influence the oncologic outcome [18-20].

Regarding perioperative results and surgical complications, rectal injury ranged from $0 \%$ to $28 \%$ in patients and anastomotic stricture from $7 \%$ to $41 \%$. Major complications (Clavien 3-5) occurred in $0-25 \%$ of patients, and estimated blood loss (EBL) varied between $119 \mathrm{~mL}$ and $1 \mathrm{~L}$. Blood transfusion rates were found to be similar to the standard RP procedures [10].

Post-SRP erectile function sufficient for sexual intercourse ranged from $0 \%$ to $20 \%$ which led to the recommendation for oral medication or surgical treatment for ED in at least $80 \%$ of patients. Post-SRP urinary continence, defined by zero pads after SRP, ranged from $21 \%$ to $90 \%$ [10].

2.4. Salvage Laparoscopic Radical Prostatectomy. The feasibility of performing salvage prostatectomies has been extended into laparoscopy and more recently into robotic platforms [21, 22 ]. In 2003, Vallancien et al. were the first to report the outcome of laparoscopic SRP in seven cases with radiorecurrent PCa. Average operating time was $190 \mathrm{~min}$ (170-210 $\mathrm{min}$ ). Two patients had positive surgical margins (PSM). At follow-up of $7,12,15$, and 21 months, four patients were free of disease. No complications were reported. Five patients were continent and two patients who were potent before surgery became impotent [21]. Stolzenburg et al. investigated the feasibility of salvage endoscopic extraperitoneal RP for locally recurrent $\mathrm{PCa}$ in 9 patients. Regarding complications, only one patient 
with urinary retention was reported. Biochemical recurrence was recognized in only one patient 12 months postoperatively. Seven patients were completely continent [23]. Liatsikos et al. reported the outcome of another series of 12 patients who underwent salvage endoscopic extraperitoneal RP. Average operative time was $153 \mathrm{~min}$, and mean blood loss was $238 \mathrm{~mL}$. No intraoperative complications were reported. Biochemical recurrence was observed in one patient 12 months postoperatively. 10 patients were completely continent, but 3 preoperatively potent patients became impotent after the operation [24].

2.5. Salvage Robot-Assisted Radical Prostatectomy. Robotassisted radical prostatectomy (RARP) is the most commonly performed surgical procedure for the treatment of patients with clinically localized prostate cancer in the United States. The robot offers several advantages, such as $3 \mathrm{D}$ vision, wristed instrumentation, motion scaling, image magnification, and tremor filtration. Hence, it may theoretically overcome the major limitations of salvage radical prostate surgery, such as the inability to identify correct surgical planes and neurovascular protection and therefore improve the oncologic and functional outcomes.

Avoidance of bladder neck contracture is very important after salvage RARP and, as a result of either the contracture or the treatment itself, these patients are at very high risk for incontinence. Watertight anastomosis with a running barbed suture may decrease the risk of anastomotic leakage and rate of bladder neck contractures.

Pneumoperitoneum may contribute to reduced blood loss compared to open salvage prostatectomy with EBL and transfusion requirements that do not appear to exceed that of primary (nonsalvage) robotic prostatectomy. However, all of these advantages may be offset by the lack of tactile feedback which is a major concern in this setting. Future improvements in haptic feedback technology are especially important in salvage surgeries where tissue planes are harder to discern.

In 2008, Jamal et al. reported a case of salvage robotassisted radical prostatectomy (sRARP) [25]. The patient previously underwent 70 Gy of conformal EBRT and 3 months of antiandrogen treatment for a Gleason 6 tumor. He presented 2 years later due to hemospermia when he had a PSA of $0.7 \mathrm{ng} / \mathrm{mL}$. Prostatic biopsy showed residual tumor and he underwent sRARP. After 3 months, the patient was continent, and his PSA was less than $0.03 \mathrm{ng} / \mathrm{mL}$. After this initial report, several case-series have been published to date (Tables 1 and 2).

The first robotic series was reported by Kaouk et al. in which four patients underwent sRARPs with a mean operative time and EBL of 125 minutes and $117 \mathrm{~mL}$, respectively. All patients had obturator lymph node dissection, and none showed any lymph node metastasis. The intraoperative courses were uneventful, but PSM occurred in two patients. At 1-month follow-up, $75 \%$ of the patients were dry on most days [22].

Subsequently, Boris et al. reported 11 patients who underwent sRARP with pelvic lymph node dissection. The mean operative time was 183 minutes, while the mean EBL was
$113 \mathrm{~mL}$. There were no intraoperative complications; however, an anastomotic leak developed in one patient necessitating extended catheterization, while an anastomotic stricture developed in another patient. Eight $(72.7 \%)$ patients were continent $(0-1 \mathrm{pad} / \mathrm{d})$, of which six were pad free. Two patients had erections adequate for sexual intercourse. After a mean follow-up of 20.5 months, 3 patients had biochemical recurrence. They also supported the feasibility of sRARP [26].

Eandi et al. have reported their series of sRARPs consisting of 18 patients. Median operative time, EBL, and length of stay were, respectively, $2.6 \mathrm{~h}, 150 \mathrm{~mL}$, and 2 days. Neither significant complications (rectal or ureteral injuries) nor need for blood transfusion was reported. Anastomotic extravasation was present in six (33\%) cases, of which an anastomotic stricture developed in three. Five (28\%) patients had a PSM, of whom two had organ-confined disease. One patient had lymph node metastasis. Six (33\%) patients were completely continent, while all patients had ED after surgery. At a median follow-up of 18 months, 12 (67\%) patients were free of biochemical recurrence [27].

Strope et al. reported the results of six patients who underwent RARP after definitive RT. The mean preoperative PSA level and the mean operative time were $9.3 \mathrm{ng} / \mathrm{mL}$ and 356 minutes, respectively. No rectal injuries or other intraoperative complications were experienced. Mean estimated blood loss was $280 \mathrm{~mL}$. None received blood transfusion. Mean duration of hospitalization was 2 days. At 1 year, 2.3 pads per day were being used in the four patients who had eligible data regarding functional status. In three patients with available data at 1 year, all reported erectile dysfunction. Margins were negative in all but one patient and none of the patients had lymph node involvement. All except for 2 patients remained free of biochemical recurrence at a mean follow-up of 15 months [28].

Recently, Chauhan et al. retrospectively identified 15 patients who underwent sRARP in three academic institutions over a 20 -month period with biopsy-proven prostate cancer after definitive radiotherapy. The median operative time, the median estimated blood loss, and the median length of hospital stay were $140.5 \mathrm{~min}, 75 \mathrm{~mL}$, and 1 day, respectively. There were no rectal injuries. Two patients had a PSM. Of the patients, $71.4 \%$ were continent. At a median follow-up of 4.6 months, four (28.6\%) patients presented with biochemical recurrence after sRARP [29].

Kaffenberger et al. reported their series of sRARP consisting of 34 patients who had surgery after the failure of prior definitive ablative therapy. Median time from primary therapy to sRARP was 48.5 months with a median preoperative PSA of $3.86 \mathrm{ng} / \mathrm{mL}$. There were 2 Clavien grade 2 and higher complications. Postoperatively, $39 \%$ of patients were continent ( $0-1 \mathrm{pad} /$ day). After a median follow-up of 16 months, $18 \%$ of patients had biochemical failure. The PSM rate was $26 \%$, of which $33 \%$ had biochemical failure after surgery. On univariable analysis, PSA doubling time and Gleason score at original diagnosis were found to be significantly associated with biochemical failure. They highlighted the advantages of sRARP as superior visualization of the posterior prostatic 
TABLE 1: Perioperative outcomes in sRARP series.

\begin{tabular}{|c|c|c|c|c|c|c|c|c|}
\hline Series & Patients, $n$ & Type of radiation & $\begin{array}{l}\text { Mean follow-up, } \\
\text { mos }\end{array}$ & $\begin{array}{c}\text { Mean EBL, } \\
\mathrm{mL} \\
\end{array}$ & $\begin{array}{l}\text { Mean OR } \\
\text { time, min }\end{array}$ & $\begin{array}{c}\text { Mean days on } \\
\text { catheter, } d\end{array}$ & $\begin{array}{l}\text { Mean hospital } \\
\text { stay, d }\end{array}$ & $\begin{array}{c}\text { Nerve } \\
\text { sparing, } n\end{array}$ \\
\hline $\begin{array}{l}\text { Jamal et al. } \\
\text { [25] }\end{array}$ & 1 & $1 \mathrm{XRT}$ & 3 & 100 & 150 & 14 & 1 & 0 \\
\hline $\begin{array}{l}\text { Kaouk et } \\
\text { al. [22] }\end{array}$ & 4 & $2 \mathrm{BT}, 2 \mathrm{XRT}+\mathrm{BT}$ & 5 & 117 & 125 & 15 & 2.7 & $0 / 4$ \\
\hline $\begin{array}{l}\text { Boris et al. } \\
{[26]}\end{array}$ & 11 & $\begin{array}{l}6 \mathrm{BT}, 4 \mathrm{XRT}, 1 \mathrm{XRT} \\
+\mathrm{BT}\end{array}$ & 20.5 & 113 & 183 & 10.4 & 1.4 & NA \\
\hline $\begin{array}{l}\text { Eandi et al. } \\
\text { [27] }\end{array}$ & 18 & 8 BT, 8 XRT, 2 PBT & 18 & 150 & 156 & 14 & 2 & NA \\
\hline $\begin{array}{l}\text { Strope et } \\
\text { al. [28] }\end{array}$ & 6 & 4 XRT, 2 BT & $>12$ & 280 & 356 & NA & 2 & 1 \\
\hline $\begin{array}{l}\text { Chauhan } \\
\text { et al. [29] }\end{array}$ & 15 & $\begin{array}{l}5 \text { XRT, } 3 \text { XRT + BT, } \\
2 \text { PBT, } 5 \text { BT }\end{array}$ & 4.6 & 75 & 138 & NA & 1 & $2 / 15$ \\
\hline $\begin{array}{l}\text { Kaffen- } \\
\text { berger et } \\
\text { al. [30] }\end{array}$ & 34 & $\begin{array}{l}13 \text { BT, } 11 \text { XRT, } 6 \text { BT } \\
+ \text { XRT, } 4 \text { HIFU }\end{array}$ & 16.1 & $\begin{array}{c}\text { NA }(88 \% \text { had } \\
\text { EBL } \leq \\
250 \mathrm{~mL})\end{array}$ & 176 & NA & $\begin{array}{c}\text { NA }(94 \% \\
\text { discharged on } \\
\text { day } 1)\end{array}$ & NA \\
\hline $\begin{array}{l}\text { Yuh et al. } \\
{[32]}\end{array}$ & 51 & $\begin{array}{l}22 \text { BT, } 18 \text { XRT, } 6 \\
\text { PBT, } 3 \text { Cryo, } 1 \\
\text { HIFU, } 1 \text { XRT + BT }\end{array}$ & 36 & 175 & 179 & 14 & 2 & NA \\
\hline
\end{tabular}

EBL: estimated blood loss; OR: operative; XRT: external-beam radiation therapy; NA: not available; BT: brachytherapy; PBT: proton beam therapy; HIFU: high intensity focused ultrasound; and Cryo: cryotherapy.

TABLE 2: Oncologic and functional outcomes in sRARP series.

\begin{tabular}{|c|c|c|c|c|c|c|c|c|}
\hline Series & Patients, $n$ & $\begin{array}{c}\text { Overall } \\
\text { complications, } n\end{array}$ & $\begin{array}{c}\text { Rectal } \\
\text { injury, } n\end{array}$ & $+\mathrm{LN}, n$ & $\begin{array}{c}\text { Continence, } \\
n\end{array}$ & Potency, $n$ & PSM, $n$ & $\begin{array}{l}\text { BCR during } \\
\text { follow-up, } n \\
\end{array}$ \\
\hline Jamal et al. [25] & 1 & 0 & 0 & 0 & $1 / 1$ & NA & $0 / 1$ & 0 \\
\hline Kaouk et al. [22] & 4 & 1 & 0 & 0 & $3 / 4$ & NA & $2 / 4$ & NA \\
\hline Boris et al. [26] & 11 & 3 & 0 & 2 & $8 / 11$ & $2 / 11$ & $3 / 11$ & 3 \\
\hline Eandi et al. [27] & 18 & 7 & 0 & 1 & $6 / 18$ & $0 / 18$ & $5 / 18$ & 6 \\
\hline Strope et al. [28] & 6 & 4 & 0 & 0 & $0 / 6$ & $0 / 6$ & $1 / 6$ & 2 \\
\hline $\begin{array}{l}\text { Chauhan et al. } \\
\text { [29] }\end{array}$ & 15 & 4 & 0 & 1 & $10 / 14$ & $0 / 15$ & $2 / 15$ & 4 \\
\hline $\begin{array}{l}\text { Kaffen-berger et } \\
\text { al. [30] }\end{array}$ & 34 & 13 & 1 & 0 & $12 / 33$ & $5 / 33$ & $9 / 34$ & 6 \\
\hline Yuh et al. [32] & 51 & 24 & 1 & 3 & $23 / 51$ & $6 / 13$ & $16 / 51$ & 10 \\
\hline
\end{tabular}

EBL: estimated blood loss; OR: operative; LN: lymph node; PSM: positive surgical margin; BCR: biochemical recurrence; and NA: not available.

plane, modest blood loss, low complication rates, and short length of stay [30].

Zugor et al. have reported the data of 13 patients who have undergone sRARP after failed external-beam radiotherapy $(n=7)$ or brachytherapy $(n=6)$. Neurovascular bundle preservation was performed in 3 patients (23.1\%). Interestingly, they did not report any major intraoperative or postoperative complication. At 12 months, 7 patients were continent (53.8\%), and 3 patients (23.1\%) were potent. During the follow-up period, only 3 patients (23.1\%) exhibited BCR [31].

The largest sRARP series has recently been published by Yuh et al. They reported the outcome of 51 consecutive patients who underwent sRARP after previous failed local therapy. Median age at surgery was 68 years and a median of 68 months has elapsed since primary treatment. Median operative time and estimated blood loss amount were 179 minutes and $175 \mathrm{~mL}$, respectively. Half of the patients had extracapsular disease on eventual histopathologic assessment and the positive surgical margin rate was $31 \%$. After a median follow-up of 36 months, their estimated 3-year biochemical recurrence or progression-free survival was $57 \%$. Noteworthy, they reported significant complications (47\%), incontinence, and erectile dysfunction rates. However, potency was maintained in $23 \%$ of preoperatively potent men and spontaneous return of urinary continence was achieved in 23 patients $(45 \%)$ with a median time to continence of 6 months. Nevertheless, they emphasized the importance of proper patient counseling and selection before sRARP [32].

2.6. Summary. Salvage RP is a surgically challenging but effective secondary local treatment of PCa that recurred after 
radiotherapy with curative intent. Recommended criteria and identified predictive factors may help to select patients who are most suitable for salvage RP with long-term cure and good functional outcome. Extensive counseling regarding possible side effects of the procedure are mandatory.

In sRARP for radiorecurrent prostate cancer, tissue planes are often obscured and there is adherence of adjacent structures such as the rectum, pubic bone, and bladder. Healing and recovery are also delayed following energy destruction of tissue. Despite the fact that complications were not reported in a standardized categorical manner, the majority of them were of high importance as they required procedural intervention for bladder neck contracture, artificial urinary sphincter, or penile prosthesis.

Available data is consisting of small case series with limited follow-up. Larger series with a longer follow-up are necessary to make definitive conclusions about the oncologic and functional outcomes.

\section{Robot-Assisted Radical Prostatectomy after Prostate Surgery}

3.1. General Considerations. It is not uncommon for men to be diagnosed of cancer on TURP chips or to develop prostate cancer later after having undergone TURP for benign prostatic obstruction. Such men may have different outcomes on radical prostatectomy compared to those who have no such previous intervention. The relative paucity of the number of patients who underwent a previous TURP makes any comparative analysis difficult and also is a reflection of the few available studies on this subject in the literature (Tables 3 and 4).

There are several important factors which may affect the outcome of post-TURP RARP. The vesicourethral anastomosis may be technically difficult as a result of the rigidity of the bladder neck and the loss of elasticity of the urethra. Previous resection of the bladder neck could also distort the position of the ureteral orifices and thus increase the risk of ureteral injury. Increased periprostatic adhesions may increase the amount of blood lost and the risk of rectal injury during RARP.

The need for bladder neck reconstruction is increased because the bladder neck is wide, which may impact anastomotic urinary leakage and continence outcomes. TURP renders the internal sphincter mechanism deficient and also places the external sphincter at risk if the proper technique is not used which may increase the cumulative risk of postprocedural incontinence. Neurovascular bundle identification may be difficult as a result of periprostatic adhesions and therefore the risk of erectile dysfunction may be increased. Urethral manipulation and catheterization during TURP may result in anterior urethral stricture formation, a fact which may lead to infravesical obstruction and cause lower urinary tract symptoms after RARP.

Moreover, lymph nodes may be enlarged secondary to reactional changes post-TURP and may be difficult to interpret on preoperative imaging. There may be an increased risk of metastatic spread of disease because of the opening of lymphovascular channels during TURP along with continuous fluid irrigation.

3.2. Open and Laparoscopic Series. Most studies comparing the oncologic and functional outcomes in patients with and without previous TURP involve perineal, retropubic, laparoscopic, and endoscopic extraperitoneal RP series, data that ignore the advantages of the robotic technique. Colombo et al. evaluated the outcome of retropubic RP after TURP. They found a mean operative time from 135 to 105 minutes in the TURP group versus from 125 to 85 minutes in the control group. Complications were encountered in up to $50 \%$ of the patients. They reported that $74 \%$ and $86 \%$ of patients were dry at 6 and 12 months, respectively, and that $28 \%$ of patients were potent at 6 months. They considered RP to be feasible in patients after TURP [33].

Jaffe et al. compared the operative and postoperative outcomes of 119 patients who underwent laparoscopic RP after TURP to that of a randomized matched control group. Mean estimated blood loss, transfusion rate, and reoperation rates were statistically similar between the 2 groups. Postoperative length of stay (6.5 versus 5.2 days) and operative time (179 versus 171 minutes) were statistically higher in the TURP group. Positive surgical margin rate was significantly higher in the TURP group compared to the non-TURP group $(21.8 \%$ versus $12.6 \%$ ). Complications were observed in 64 patients in the TURP group compared to 34 in the non-TURP group $(p<0.01)$. Five $(4.2 \%)$ and $2(1.7 \%)$ men in the TURP and non-TURP groups, respectively, underwent reoperation during the postoperative period $(P=0.13)$ [34].

In a study by Teber et al., the authors evaluated the effect of previous TURP on surgical, functional, and oncologic outcomes after laparoscopic RP in comparison with a control group. The positive surgical margin rates were $14.5 \%$ and $16.3 \%$, and the long-term continence rates were similar; however, previous TURP was associated with a lower continence rate $(49.1 \%)$ at 3 months compared with $61.8 \%$ for the control group. There was no significant difference in the potency rates between the two groups at 12 months [35].

3.3. Robotic Series. Martin et al. were the first to investigate the effect of previous prostatic surgery on the outcome of robot-assisted RP. They evaluated the data of 24 patients who underwent RARP with a history of at least one previous treatment to the prostate including TURP, transurethral incision of the prostate (TUIP), transurethral microwave thermotherapy (TUMT), transurethral needle ablation (TUNA), photoselective vaporization of the prostate (PVP), simple prostatectomy, and open bladder neck reconstruction (group 1) and compared that of 486 patients with no treatment prior to RARP (group 2). Mean estimated blood loss, length of hospital stay, and operative duration were not statistically significantly different. However, the catheter time was significantly longer in group 1 (12 versus 8 days, $P=0.028$ ). Complication rates were comparable ( $8.3 \%$ versus $6.8 \%)$. There were no bowel injuries in either group. The combined, overall PSM rate was $20.8 \%$ and $22.6 \%$ in groups 1 and 2 , respectively $(P=1.0)$. Overall, there was no statistically 
TABLE 3: Perioperative outcomes in clinical series consisting of patients who underwent RARP after prostate surgery.

\begin{tabular}{|c|c|c|c|c|c|c|c|}
\hline Series & Study population & $\begin{array}{c}\text { Mean } \\
\text { follow-up, mos }\end{array}$ & $\begin{array}{l}\text { Mean EBL, } \\
\text { mL }\end{array}$ & $\begin{array}{l}\text { Mean OR } \\
\text { time, min }\end{array}$ & $\begin{array}{l}\text { Mean days on } \\
\text { catheter, } \mathrm{d}\end{array}$ & $\begin{array}{l}\text { Mean hospital } \\
\text { stay, d }\end{array}$ & $\begin{array}{c}\text { Nerve } \\
\text { sparing, } n\end{array}$ \\
\hline $\begin{array}{l}\text { Zugor et al. } \\
\text { [38] }\end{array}$ & $\begin{array}{l}80 \text { pts with TURP before } \\
\text { RARP versus } 80 \text { pts with } \\
\text { RARP }\end{array}$ & 13.5 & 165 versus 144 & 189 versus 149 & 6.8 versus 5.2 & NA & $\begin{array}{c}42 \text { versus } \\
54\end{array}$ \\
\hline $\begin{array}{l}\text { Martin et al. } \\
{[36]}\end{array}$ & $\begin{array}{l}24 \text { pts with previous } \\
\text { treatment to the prostate } \\
\text { and RARP versus } 486 \\
\text { with no previous } \\
\text { treatment and RARP }\end{array}$ & NA & 155 versus 137 & $\begin{array}{l}200 \text { versus } \\
186\end{array}$ & $\begin{array}{l}12 \text { versus } 8 \\
(P=0.028)\end{array}$ & 2.2 versus 1.5 & $\begin{array}{c}14 \text { versus } \\
403\end{array}$ \\
\hline $\begin{array}{l}\text { Gupta et al. } \\
\text { [37] }\end{array}$ & $\begin{array}{l}18 \text { pts with TURP before } \\
\text { RARP versus } 8 \text { pts with } \\
\text { pT1b CaP and RARP } \\
\text { versus } 132 \text { pts with RARP }\end{array}$ & 15.3 & $\begin{array}{c}4941 \text { versus } \\
358.3 \text { versus } \\
324.2 \\
(P=0.03)\end{array}$ & $\begin{array}{c}189.1 \text { versus } \\
162.5 \text { versus } \\
166\end{array}$ & $\begin{array}{l}15.5 \text { versus } \\
14.2 \text { versus } \\
13.3\end{array}$ & $\begin{array}{l}4.4 \text { versus } 4.1 \\
\text { versus } 3.2\end{array}$ & NA \\
\hline $\begin{array}{l}\text { Martin- } \\
\text { schek et al. } \\
{[39]}\end{array}$ & $\begin{array}{l}19 \text { pts with previous } \\
\text { TURP and RARP versus } \\
19 \text { pts with previous } \\
\text { TURP and RRP }\end{array}$ & NA & $\begin{array}{l}333 \text { versus } \\
\quad 1103 \\
(P<0.001)\end{array}$ & $\begin{array}{l}217 \text { versus } 174 \\
\quad(P=0.02)\end{array}$ & $\begin{array}{c}7.9 \text { versus } 11.7 \\
(P=0.001)\end{array}$ & $\begin{array}{c}8.5 \text { versus } 11.7 \\
(P=0.003)\end{array}$ & $\begin{array}{c}14 \text { versus } \\
13\end{array}$ \\
\hline
\end{tabular}

TURP: transurethral resection of the prostate; RARP: robot-assisted radical prostatectomy; CaP: prostate cancer; EBL: estimated blood loss; OR: operating; and NA: not available.

TABLE 4: Oncologic and functional outcomes in clinical series consisting of patients who underwent RARP after prostate surgery.

\begin{tabular}{|c|c|c|c|c|c|c|c|c|}
\hline Series & Study population & $\begin{array}{c}\text { Transfusion, } \\
n\end{array}$ & $\begin{array}{c}\text { Rectal } \\
\text { injury, } n\end{array}$ & $+\mathrm{LN}, n$ & $\begin{array}{c}\text { Continence, } \\
n\end{array}$ & Potency, $n$ & $\operatorname{PSM}, n$ & $\begin{array}{l}\text { BCR during } \\
\text { f/u, } n\end{array}$ \\
\hline $\begin{array}{l}\text { Zugor et al. } \\
\text { [38] }\end{array}$ & $\begin{array}{l}80 \text { pts with TURP before } \\
\text { RARP versus } 80 \text { pts with } \\
\text { RARP }\end{array}$ & 1 versus 0 & 1 versus 0 & $\begin{array}{c}2 \text { versus } \\
0\end{array}$ & 70 versus 73 & 38 versus 58 & 6 versus 4 & NA \\
\hline $\begin{array}{l}\text { Martin et al. } \\
{[36]}\end{array}$ & $\begin{array}{l}24 \text { pts with previous } \\
\text { treatment to the prostate } \\
\text { and RARP versus } 486 \\
\text { with no previous } \\
\text { treatment and RARP }\end{array}$ & 0 versus 0 & 0 versus 0 & NA & NA & NA & 5 versus 110 & NA \\
\hline $\begin{array}{l}\text { Gupta et al. } \\
\text { [37] }\end{array}$ & $\begin{array}{l}18 \text { pts with TURP before } \\
\text { RARP versus } 8 \text { pts with } \\
\text { pT1b CaP and RARP } \\
\text { versus } 132 \text { pts with RARP }\end{array}$ & $\begin{array}{l}2 \text { versus } 1 \\
\text { versus } 9\end{array}$ & $\begin{array}{c}0 \text { versus } 0 \\
\text { versus } 0\end{array}$ & $\begin{array}{c}0 \text { versus } \\
0 \text { versus } \\
3\end{array}$ & $\begin{array}{l}6 / 8 \text { versus } \\
5 / 6 \text { versus } \\
78 / 85\end{array}$ & $\begin{array}{c}1 / 5 \text { versus } 1 / 3 \\
\text { versus } 20 / 61\end{array}$ & $\begin{array}{l}4 \text { versus } 1 \\
\text { versus } 17\end{array}$ & $\begin{array}{l}3 \text { versus } 1 \\
\text { versus } 9 \\
(P=0.04)\end{array}$ \\
\hline $\begin{array}{l}\text { Martinschek } \\
\text { et al. [39] }\end{array}$ & $\begin{array}{l}19 \text { pts with previous } \\
\text { TURP and RARP versus } \\
19 \text { pts with previous } \\
\text { TURP and RRP }\end{array}$ & $\begin{array}{c}0 \text { versus } 2 \\
(P<0.001)\end{array}$ & 0 versus 0 & NA & NA & NA & 3 versus 3 & NA \\
\hline
\end{tabular}

TURP: transurethral resection of the prostate; RARP: robot-assisted radical prostatectomy; CaP: prostate cancer; LN: lymph node; PSM: positive surgical margin; BCR: biochemical recurrence; and NA: not available.

significant difference in perioperative outcomes between the groups [36].

In the subsequent study conducted by Gupta et al., 158 cases of RARP for clinically localized prostate cancer, including 26 cases that had undergone previous TURP and 132 cases without TURP were analyzed in terms of surgical, oncological, and functional outcomes. The TURP cases were further subclassified into those who were found to have cancer after the histopathologic examination of TURP chips and those who had benign histopathology on TURP chips but developed cancer on subsequent follow-up. Post-TURP patients were found to have significantly greater blood loss (494 versus $324 \mathrm{~mL}$ ) and a need for bladder neck reconstruction (26.7\% versus $9.7 \%$ ) compared to the non-TURP group. Conversion rates were also higher in TURP group $(7.7 \% ; 2 / 26)$ compared to non-TURP group (3\%; 4/132). Importantly, all conversions in TURP were noted in those who had cT1b disease. Surgical time (189 versus $166 \mathrm{~min}$ ), margin positivity rate, and biochemical recurrence rate were also higher in the TURP group. Regarding functional outcomes, incontinence rates in TURP group were higher both at $6(14 \%$ versus $11.8 \%)$ and 12 (25\% versus $8 \%)$ months follow-up than that of non-TURP group [37].

Zugor et al. compared the perioperative, oncologic, and functional outcomes of the patients who had undergone TURP before RARP $(n=80)$ and those who underwent 
RARP without a history of TURP $(n=80)$. Groups had equivalent clinicopathologic characteristics in this matchedpair analysis. Regarding preoperative characteristics, the only statistically significant difference was between potency rates (67.5\% in TURP group versus $83.75 \%$ in non-TURP group, $P=0.056)$. The need for bladder neck reconstruction and operative time was significantly higher in the TURP group compared to the non-TURP group (58.7\% versus $2.5 \%, P=$ 0.073 and $189 \mathrm{~min}$ versus $149 \mathrm{~min}, P=0.069$, respectively). The PSM rate did not exhibit statistical significance between two groups (6.25\% versus 5\%). Continence and potency rates in 12 months were similar $(87.5 \% / 91.25 \%$ and $70.3 \% / 86.5 \%$, respectively) [38].

Martinschek et al. compared the surgical outcome of robot-assisted radical prostatectomy and radical retropubic prostatectomy (RRP) in patients who underwent TURP. Mean operative time was 217 minutes for RARP and 174 minutes for RRP $(P<0.05)$. The overall positive surgical margin rate was $15.8 \%$ in both groups. Mean estimated blood loss was $33 \mathrm{~mL}$ in RARP patients and $1103 \mathrm{~mL}$ in RRP patients $(P<0.001)$. The RARP and RRP groups also differed in terms of hospital stay (8.58 versus 11.74 days; $P=0.0037$ ), duration of catheterization (7.95 versus 11.78 days; $P=0.0016$ ), postoperative complications according to the Clavien classification system (6 versus 15 patients; $P=$ $0.0027)$, and transfusion rate ( $0 \%$ versus $10.5 \% ; P<0.001)$. They concluded that robot-assisted radical prostatectomy may be more feasible while dealing with prostate cancer patient who had undergone TURP [39].

Several newer modifications of TURP (e.g., transurethral vaporization resection of the prostate, bipolar TURP) and several types of laser prostatectomy (e.g., photoselective vaporization, holmium laser enucleation of the prostate, etc.) are available with each having its advantages and disadvantages. It may be possible that that these different technologies produce different degrees of prostatic, periprostatic, and bladder neck changes and may, therefore, have different degrees of impact on the outcomes of RARP. A recent study has reported on the feasibility of RARP after holmium laser enucleation of the prostate [40]. Apart from the technology used to resect the prostate, there are several other factors that may influence the final outcome. These include the size of the prostate gland, resection time, depth and completeness of resected prostate, presence of prostatitis, infection, surgeon's technique, and an individual's immune response. These factors directly affect the degree of inflammatory response in and around the prostate after TURP and may play important roles with respect to individual patient outcome.

3.4. Summary. The existing literature deals mainly with the post-TURP open and laparoscopic radical prostatectomies. Data is relatively scarce about the outcomes of RARP performed after prostate surgery. Some of the papers suggest that relatively poorer outcomes are achieved in men with previous pelvic or prostatic surgery. There are also suggestions that although surgery may be technically more difficult, overall morbidity, complications, and long-term functional or oncological outcomes are not different between these groups.
In conclusion, RARP is feasible after TURP, with good overall results being achieved. However, previous prostate surgery can cause difficulties for the surgical team during radical prostatectomy. Although previous TURP should not be considered as a contraindication for RARP, patients should be made aware of the above facts before undergoing RARP.

\section{Conflict of Interests}

The authors declare that there is no conflict of interests regarding the publication of this paper.

\section{References}

[1] F. J. Fowler Jr., M. J. Barry, G. Lu-Yao, J. H. Wesson, and L. Bin, "Outcomes of external-beam radiation therapy for prostate cancer: a study of medicare beneficiaries in three surveillance, epidemiology, and end results areas," Journal of Clinical Oncology, vol. 14, no. 8, pp. 2258-2265, 1996.

[2] A. Heidenreich, J. Bellmunt, M. Bolla et al., "EAU guidelines on prostate cancer. Part 1: screening, diagnosis, and treatment of clinically localised disease," European Urology, vol. 59, no. 1, pp. 61-71, 2011.

[3] M. Roach III, G. Hanks, H. Thames Jr. et al., "Defining biochemical failure following radiotherapy with or without hormonal therapy in men with clinically localized prostate cancer: recommendations of the RTOG-ASTRO Phoenix Consensus Conference," International Journal of Radiation Oncology Biology Physics, vol. 65, no. 4, pp. 965-974, 2006.

[4] N. Mottet, J. Bellmunt, M. Bolla et al., "EAU guidelines on prostate cancer. Part II. Treatment of advanced, relapsing, and castration-resistant prostate cancer," European Urology, vol. 59, no. 4, pp. 572-583, 2011.

[5] M. Kimura, V. Mouraviev, M. Tsivian, J. M. Mayes, T. Satoh, and T. J. Polascik, "Current salvage methods for recurrent prostate cancer after failure of primary radiotherapy," BJU International, vol. 105, no. 2, pp. 191-201, 2010.

[6] G. D. Grossfeld, Y. Li, D. P. Lubeck, J. M. Broering, S. S. Mehta, and P. R. Carroll, "Predictors of secondary cancer treatment in patients receiving local therapy for prostate cancer: data from cancer of the prostate strategic urologic research endeavor," Journal of Urology, vol. 168, no. 2, pp. 530-535, 2002.

[7] B. T. Chen and D. P. Wood Jr., "Salvage prostatectomy in patients who have failed radiation therapy or cryotherapy as primary treatment for prostate cancer," Urology, vol. 62, supplement, pp. 69-78, 2003.

[8] M. Garzotto and Z. Wajsman, "Androgen deprivation with salvage surgery for radiorecurrent prostate cancer: results at 5year followup," Journal of Urology, vol. 159, no. 3, pp. 950-955, 1998.

[9] E. Rogers, M. Ohori, V. S. Kassabian, T. M. Wheeler, and P. T. Scardino, "Salvage radical prostatectomy: outcome measured by serum prostate specific antigen levels," Journal of Urology, vol. 153, no. 1, pp. 104-110, 1995.

[10] D. C. Chade, J. Eastham, M. Graefen et al., "Cancer control and functional outcomes of salvage radical prostatectomy for radiation-recurrent prostate cancer: a systematic review of the literature," European Urology, vol. 61, no. 5, pp. 961-971, 2012.

[11] D. R. Mador, R. P. Huben, Z. Wajsman, and J. E. Pontes, "Salvage surgery following radical radiotherapy for adenocarcinoma of 
the prostate," The Journal of Urology, vol. 133, no. 1, pp. 58-60, 1985.

[12] N. J. Touma, J. I. Izawa, and J. L. Chin, "Current status of local salvage therapies following radiation failure for prostate cancer," Journal of Urology, vol. 173, no. 2, pp. 373-379, 2005.

[13] L. Cheng, T. J. Sebo, J. Slezak et al., "Predictors of survival for prostate carcinoma patients treated with salvage radical prostatectomy after radiation therapy," Cancer, vol. 83, no. 10, pp. 2164-2171, 1998.

[14] C. L. Amling, S. E. Lerner, S. K. Martin, J. M. Slezak, M. L. Blute, and H. Zincke, "Deoxyribonucleic acid ploidy and serum prostate specific antigen predict outcome following salvage prostatectomy for radiation refractory prostate cancer," Journal of Urology, vol. 161, no. 3, pp. 857-863, 1999.

[15] F. J. Bianco Jr., P. T. Scardino, A. J. Stephenson, C. J. DiBlasio, P. A. Fearn, and J. A. Eastham, "Long-term oncologic results of salvage radical prostatectomy for locally recurrent prostate cancer after radiotherapy," International Journal of Radiation Oncology Biology Physics, vol. 62, no. 2, pp. 448-453, 2005.

[16] K. M. Sanderson, D. F. Penson, J. Cai et al., "Salvage radical prostatectomy: quality of life outcomes and long-term oncological control of radiorecurrent prostate cancer ", Journal of Urology, vol. 176, no. 5, pp. 2025-2032, 2006.

[17] E. L. Gheiler, M. V. Tefilli, R. Tiguert et al., "Predictors for maximal outcome in patients undergoing salvage surgery for radio-recurrent prostate cancer," Urology, vol. 51, no. 5, pp. 789795, 1998.

[18] A. Heidenreich, S. Richter, D. Thüer, and D. Pfister, "Prognostic parameters, complications, and oncologic and functional outcome of salvage radical prostatectomy for locally recurrent prostate cancer after 21st-century radiotherapy," European Urology, vol. 57, no. 3, pp. 437-445, 2010.

[19] G. T. Gotto, L. H. Yunis, K. Vora, J. A. Eastham, P. T. Scardino, and F. Rabbani, "Impact of prior prostate radiation on complications after radical prostatectomy," Journal of Urology, vol. 184, no. 1, pp. 136-142, 2010.

[20] E. Rogers, M. Ohori, V. S. Kassabian, T. M. Wheeler, and P. T. Scardino, "Salvage radical prostatectomy: Outcome measured by serum prostate specific antigen levels," Journal of Urology, vol. 153, no. 1, pp. 104-110, 1995.

[21] G. Vallancien, R. Gupta, X. Cathelineau, H. Baumert, and F. Rozet, "Initial results of salvage laparoscopic radical prostatectomy after radiation failure," The Journal of Urology, vol. 170, no. 5, pp. 1838-1840, 2003.

[22] J. H. Kaouk, J. Hafron, R. Goel, G. Haber, and J. S. Jones, "Robotic salvage retropubic prostatectomy after radiation/brachytherapy: initial results," BJU International, vol. 102, no. 1, pp. 93-96, 2008.

[23] J. Stolzenburg, B. Bynens, M. Do, R. Rabenalt, P. F. Katsakiori, and E. Liatsikos, "Salvage laparoscopic extraperitoneal radical prostatectomy after failed high-intensity focused ultrasound and radiotherapy for localized prostate cancer," Urology, vol. 70, no. 5, pp. 956-960, 2007.

[24] E. Liatsikos, B. Bynens, R. Rabenalt, P. Kallidonis, M. Do, and J. Stolzenburg, "Treatment of patients after failed high intensity focused ultrasound and radiotherapy for localized prostate cancer: salvage laparoscopic extraperitoneal radical prostatectomy," Journal of Endourology, vol. 22, no. 10, pp. 22952298, 2008.
[25] K. Jamal, B. Challacombe, O. Elhage, R. Popert, R. Kirby, and P. Dasgupta, "Successful salvage robotic-assisted radical prostatectomy after external beam radiotherapy failure," Urology, vol. 72, no. 6, pp. 1356-1358, 2008.

[26] R. S. Boris, A. Bhandari, L. S. Krane, D. Eun, S. Kaul, and J. O. Peabody, "Salvage robotic-assisted radical prostatectomy: initial results and early report of outcomes," BJU International, vol. 103, no. 7, pp. 952-956, 2009.

[27] J. A. Eandi, B. A. Link, R. A. Nelson et al., "Robotic assisted laparoscopic salvage prostatectomy for radiation resistant prostate cancer," Journal of Urology, vol. 183, no. 1, pp. 133-137, 2010.

[28] S. A. Strope, M. Coelho, D. P. Wood, and B. K. Hollenbeck, "Robot-assisted salvage prostatectomy: evaluation of initial patient-reported outcomes," Journal of Endourology, vol. 24, no. 3, pp. 425-427, 2010.

[29] S. Chauhan, M. B. Patel, R. Coelho et al., "Preliminary analysis of the feasibility and safety of salvage robot-assisted radical prostatectomy after radiation failure: multi-institutional perioperative and short-term functional outcomes," Journal of Endourology, vol. 25, no. 6, pp. 1013-1019, 2011.

[30] S. D. Kaffenberger, K. A. Keegan, N. K. Bansal et al., "Salvage robotic assisted laparoscopic radical prostatectomy: a single institution, 5-year experience," Journal of Urology, vol. 189, no. 2, pp. 507-513, 2013.

[31] V. Zugor, A. P. Labanaris, D. Porres, A. Heidenreich, and J. H. Witt, "Robot-assisted radical prostatectomy for the treatment of radiation-resistant prostate cancer: surgical, oncological and short-term functional outcomes," Urologia Internationalis, vol. 92, no. 1, pp. 20-26, 2014.

[32] B. Yuh, N. Ruel, S. Muldrew et al., "Complications and outcomes of robot-assisted salvage radical prostatectomy-a single institution experience," BJU International, vol. 113, no. 5, pp. 769776, 2014.

[33] R. Colombo, R. Naspro, A. Salonia et al., "Radical prostatectomy after previous prostate surgery: clinical and functional outcomes," The Journal of Urology, vol. 176, no. 6, part 1, pp. 2459-2463, 2006.

[34] J. Jaffe, O. Stakhovsky, X. Cathelineau, E. Barret, G. Vallancien, and F. Rozet, "Surgical outcomes for men undergoing laparoscopic radical prostatectomy after transurethral resection of the prostate," Journal of Urology, vol. 178, no. 2, pp. 483-487, 2007.

[35] D. Teber, J. Cresswell, M. Ates et al., "Laparoscopic radical prostatectomy in clinical Tla and Tlb prostate cancer: oncologic and functional outcomes-a matched-pair analysis," Urology, vol. 73, no. 3, pp. 577-581, 2009.

[36] A. D. Martin, P. J. Desai, R. N. Nunez et al., "Does a history of previous surgery or radiation to the prostate affect outcomes of robot-assisted radical prostatectomy?" BJU International, vol. 103, no. 12, pp. 1696-1698, 2009.

[37] N. P. Gupta, P. Singh, and R. Nayyar, "Outcomes of robotassisted radical prostatectomy in men with previous transurethral resection of prostate," BJU International, vol. 108, no. 9, pp. 1501-1505, 2011.

[38] V. Zugor, A. P. Labanaris, D. Porres, and J. H. Witt, "Surgical, oncologic, and short-term functional outcomes in patients undergoing robot-assisted prostatectomy after previous transurethral resection of the prostate," Journal of Endourology, vol. 26, no. 5, pp. 515-519, 2012.

[39] A. Martinschek, K. Heinzelmann, M. Ritter, E. Heinrich, and L. Trojan, "Radical prostatectomy after previous transurethral 
resection of the prostate: robot-assisted laparoscopic versus open radical prostatectomy in a matched-pair analysis," Journal of Endourology, vol. 26, no. 9, pp. 1136-1141, 2012.

[40] N. Suardi, V. Scattoni, A. Briganti et al., "Nerve-sparing radical retropubic prostatectomy in patients previously submitted to Holmium laser enucleation of the prostate for bladder outlet obstruction due to benign prostatic enlargement," European Urology, vol. 53, no. 6, pp. 1180-1185, 2008. 


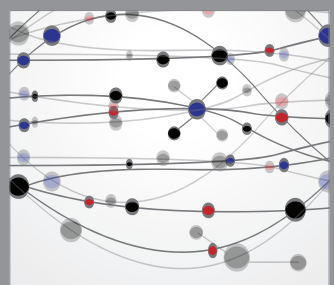

The Scientific World Journal
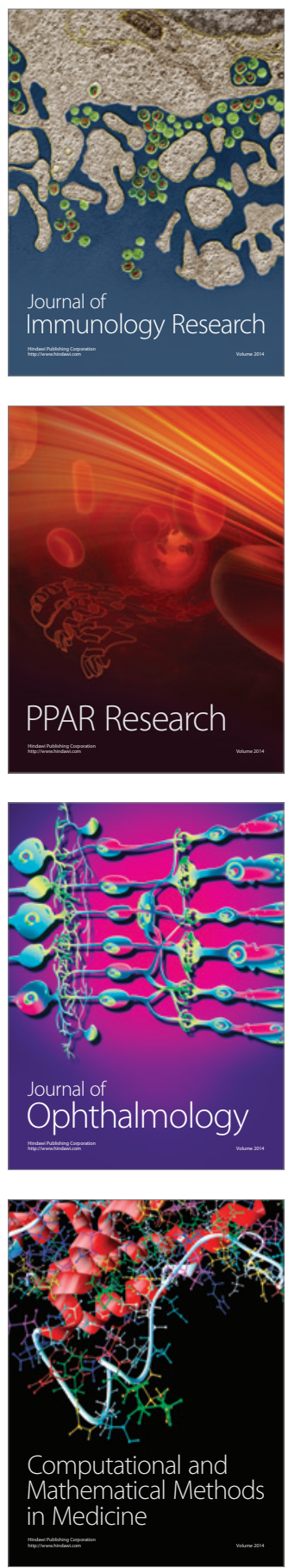

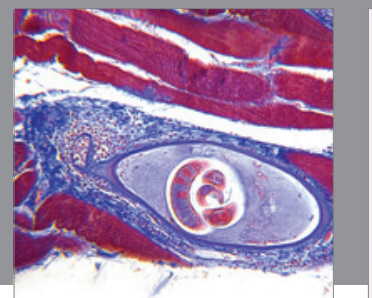

Gastroenterology

Research and Practice
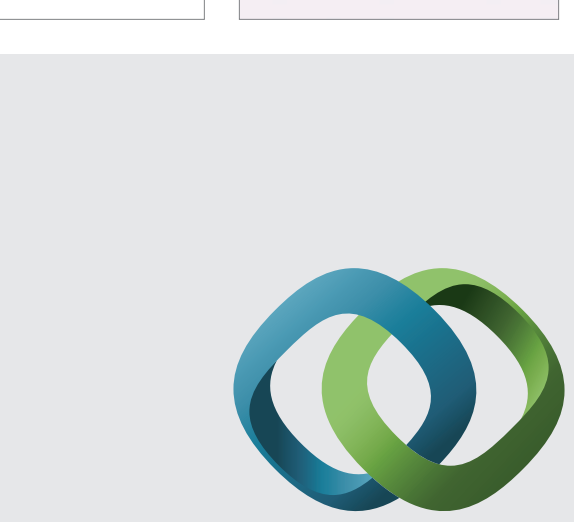

\section{Hindawi}

Submit your manuscripts at

http://www.hindawi.com
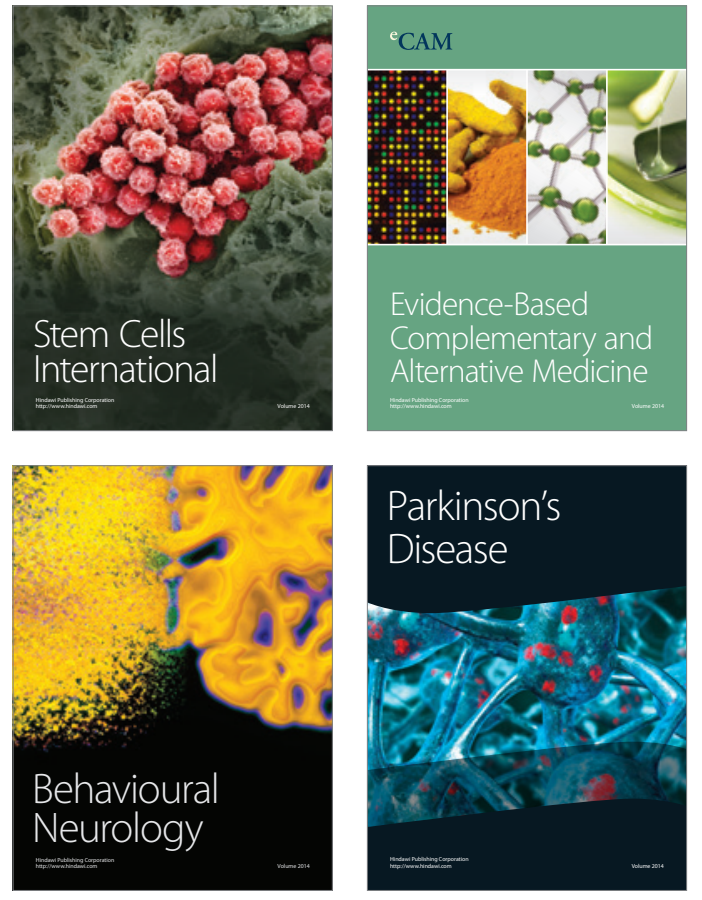
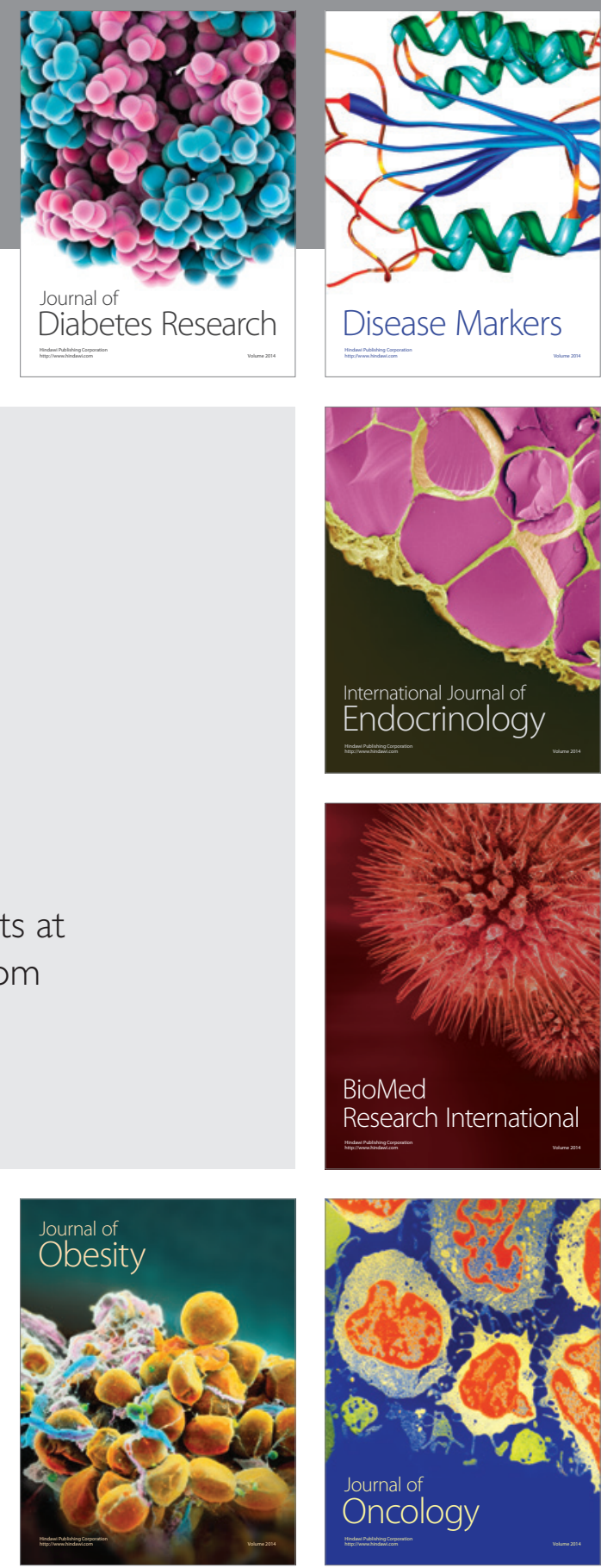

Disease Markers
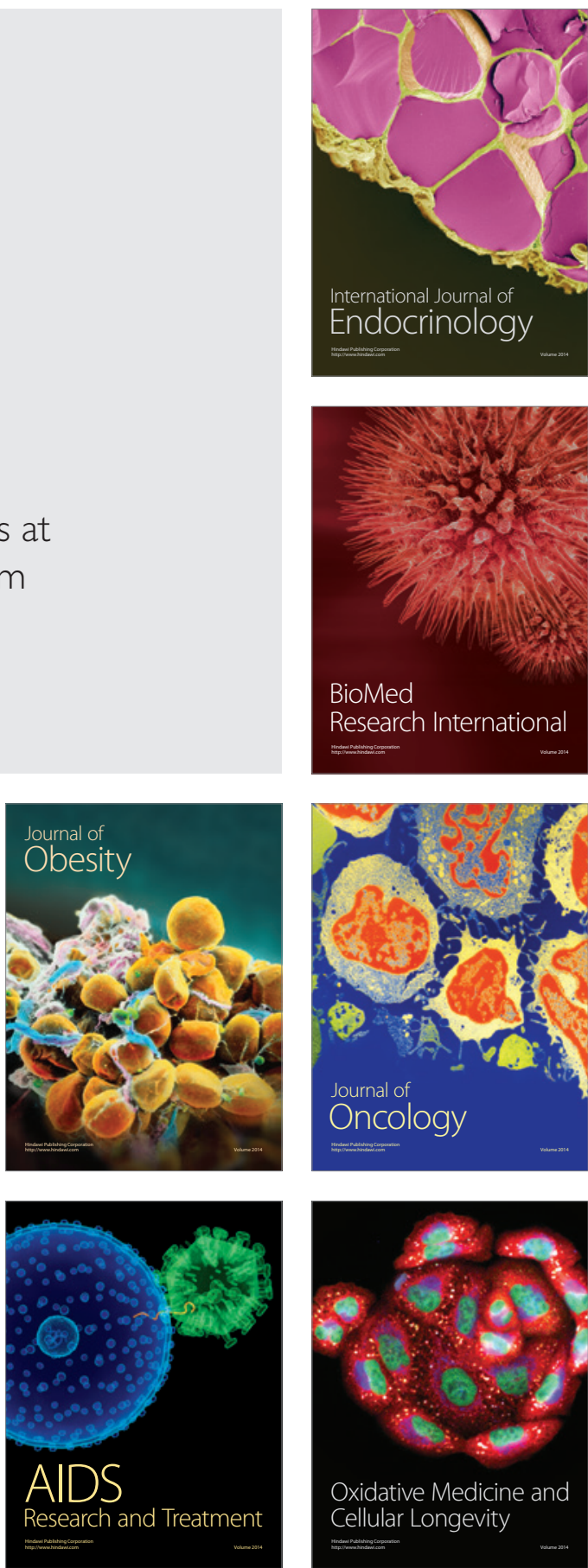